\title{
Melatonin pretreatment can improve the therapeutic effect of Adipose-derived Stem Cells on CCl4- induced liver fibrosis
}

\section{Ziqiang Zhang}

Henan University of Science and Technology

\section{Yingying Sun}

Henan University of Science and Technology

Haojie Wang

Henan University of Science and Technology

Yuxiang Yang

Henan University of Science and Technology

\section{Ruiqi Dong}

Henan University of Science and Technology

\section{Yaolu Xu}

Henan University of Science and Technology

\section{Mengyu Zhang}

Henan University of Science and Technology

Qiongxia Lv

Henan University of Science and Technology

\section{Xiaoguang Chen}

Henan University of Science and Technology

yumei liu ( $\square$ yumeiliu@haust.edu.cn )

Henan University of Science and Technology https://orcid.org/0000-0002-3687-1815

\section{Research Article}

Keywords: Melatonin (Mel), Adipose mesenchymal stem cells (ADSCs), CCL4, Liver fibrosis

Posted Date: September 7th, 2021

DOI: https://doi.org/10.21203/rs.3.rs-868703/v1

License: (c) (1) This work is licensed under a Creative Commons Attribution 4.0 International License.

Read Full License 


\section{Abstract}

\section{Background and Purpose}

In this study, the therapeutic effect of Mel-incubated ADSCs on $\mathrm{CCl}_{4}$-induced hepatic fibrosis was investigated.

\section{Methods}

The experiment was arranged into ADSCS group, ADSCS + Mel group, Model group and Control group with 10 mice in each group. The other three groups of mice were intraperitoneally injected with $8 \% \mathrm{CCl}_{4}$, and the control group was injected with the same dose of PBS twice a week for 4 weeks. From the fifth week, ADSCs group and ADSCs + Mel group mice were injected with $1 \times 10^{6}$ cells $/ 1 \mathrm{ml}$ PBS dose of ADSCs and $50 \mu \mathrm{M}$ Mel pretreated ADSCs into tail vein, respectively, twice a week for 2 weeks, and mice in the control and model groups were injected with the same dose of PBS. Samples were tested after six weeks.

\section{Results}

In model group, severe histomathological changes were observed in liver, including severe vacuolation, nuclear fragmentation and liver fibrosis, and these changes were ameliorated by Mel pretreated ADSCs. At the same time, RT-qPCR results showed that Mel-induced ADSCs significantly inhibited the expression of pro-apoptotic genes (Caspase-8, Bax and Caspase-3), and promoted the expression of anti-apoptotic gene (Bcl-2). Immunohistochemical results showed that a large number of MMP-9, TGF- $\beta$, MMP-2 yellowstained positive cells were found in the liver tissues of the model group, while the expression of positive cells was blocked by Mel-induced ADSCs.

\section{Conclusion and Implications}

ADSCs pretreated with Mel significantly improved $\mathrm{CCl}_{4}$-induced liver fibrosis, which provides a reference for clinical treatment of liver injury with mesenchymal stem cells.

\section{Introduction}

The largest solid organ and digestive gland in the body is thought to be the liver, for example, which plays a key role in purifying toxic chemicals, synthesizing new molecules, and storing and metabolizing nutrients(Trefts, Gannon, \& Wasserman, 2017). Although the liver has a strong regenerative capacity, sustained and chronic injury induced by internal and external factors can lead to liver fibrosis(Kung \& Forbes, 2009). For example, stimuli such as hepatitis virus, alcohol, and autoimmunity attack normal liver cells, resulting in liver cell damage, endothelial barrier damage, activation of inflammatory cells and hepatic stellate cells (HSCs), and damage to normal liver structure and function(Eom, Shim, \& Baik, 2015). Eventually lead to the occurrence of liver fibrosis. Up to now, some studies have indicated that abnormal activation and proliferation of HSCs are the key factors leading to liver fibrosis(Aydın \& Akçalı, 
2018; Zhou, Zhang, \& Qiao, 2014). On the one hand, HSCs break down the balance of Extracellular matrix (ECM) in the liver by synthesizing a large amount of ECM, resulting in excessive ECM deposition and continuous proliferation of collagen fibers in the liver. On the other hand, the intracellular hepatic sinus pressure is continuously increased by cell contraction, resulting in hyperplasia of collagen fibers. These two changes ultimately promote the formation of liver fibrosis(Sun \& Kisseleva, 2015). If not treated promptly, with the development of the disease will produce a large number of fibrous nodules, so that the normal liver structure and function is destroyed. The disease eventually developed into cirrhosis and even liver cancer. At present, it is known that liver transplantation is still one of the effective methods for the treatment of liver fibrosis, but due to its limited source and severe immune rejection, it is difficult to get effective and extensive treatment(Fallowfield \& Iredale, 2004).

Stem cells are not only self-replicating but also have the potential for multidirectional differentiation, which can constantly self-renew and transform into cells that form human tissues or organs under specific conditions. In recent years, stem cells transplantation has been regarded as a very effective alternative therapy for the treatment of liver diseases due to their own advantages and posttransplantation research(Z. Zhang \& Wang, 2013). Studies have shown that stem cells (embryonic stem cells, hematopoietic stem cells, and mesenchymal stem cells) can be differentiated into hepatocyte-like cells, both in vitro and in vivo(Kia et al., 2013; Shu et al., 2004; Si-Tayeb et al., 2010). Among the above stem cell types, it is known that fat-derived stem cells (adipose-derived stem Cells, ADSCs), as the name suggests, are derived from adipose tissue, with the advantages of rich, easy to obtain, strong proliferative ability and in vivo expansion(Strem, Hicok, Min, Wulur, \& Hedrick, 2005; Zuk et al., 2001). In addition, ADSCs has immunoremodulatory characteristics to migrate to the injured tissue area and secrete nutrients such as factors including growth and cytokines, which promote the repair and regeneration of damaged organs and tissues such as the liver(Eom et al., 2015). Studies have found that after transplantation of ADSCs into $\mathrm{CCl}_{4}$-induced liver fibrosis mice, the abnormally elevated levels of Alanine aminotransferase (ALT) and Aspartate aminotransferase (AST) in the serum of the mice gradually decreased and became normal, indicating that ADSCs had an obvious protective effect on the damaged liver(Banas et al., 2008). Although ADSCs transplantation has many positive effects on the treatment of liver fibrosis, there are still some deficiencies in ADSCs transplantation. For example, the survival rate of ADSCs transplantation is relatively low, and it is greatly affected by the microenvironment in vivo, so a good microenvironment is needed to play a better role. In vitro induced differentiation of hepatocyte-like cells still cannot be compared with mature liver cells an. Therefore, it is of great significance to study how to improve the survival rate of ADSCs after transplantation and how to improve its paracrine effect.

Melatonin (Mel) is secreted by the pineal gland at night and the gastrointestinal tract during the day(Margheri et al., 2012). It is responsible for a variety of physiological functions, including the antioxidants, anti-apoptotic, and pro-apoptotic activities(K. Mortezaee, 2018; Keywan Mortezaee \& Khanlarkhani, 2017; Shibo et al., 2017). Numerous existing studies have shown that Mel can promote the proliferation and differentiation of stem cells to some extent. For example, Kumar et al. found that Mel can promote the growth and proliferation of embryonic stem cells (ESCs)(Kumar et al., 2012). Fu et al. 
showed that Mel can promote the proliferation of neural stem cells (NSCs) under hypoxic conditions(Fu et al., 2011). And Mel also a vital role in the differentiation, survival and migration of NSCs(Jiaqi et al., 2016). In addition, BMMSCs pretreated with Mel obtained better therapeutic effects in myocardial infarction, cerebral ischemia and renal ischemia models(Y. Tang et al., 2014). And Mel can promote the differentiation of dental pulp stem cells (DPSCs) into hepatocytes and help to reverse liver fibrosis(Cho, Noh, Jue, Lee, \& Kim, 2015). Here, we used Mel to incubate ADSCs for 24 hours to explore the therapeutic effect of $\mathrm{CCl}_{4}$-induced liver fibrosis.

\section{Materials And Methods}

\subsection{Cell isolation and culture}

The adipose tissue was isolated from the groin of 3-week old mice and minced under sterile conditions. Next, the separated adiposing tissues were digested with $0.1 \%$ collagenase tm at $37^{\circ} \mathrm{C}$ for $60 \mathrm{~min}$, and the digestion was terminated with $10 \%$ FBS. After centrifugation, it was added to the medium, cultured in the incubator for 24 hours, and replaced to remove unattached cells and impurities. Mice ADSCs were subcultured twice before the experiment. (DMEM; FBS; Gibco; Thermo Fisher Scientific, Inc.)

\subsection{Preconditioning of ADSCs with Mel}

According to previous studies, the third generation ADSCs were incubated for $24 \mathrm{~h}$ with $50 \mu \mathrm{M} \mathrm{Mel}$ (M5250-1G; Sigma, St. Louis, USA).

\subsection{Animals}

Male Kunming mice $(n=50)$, weighing $20 \pm 2 \mathrm{~g}$, were purchased from Animal Center of Medical College of Henan University of Science and Technology (Luoyang, Henan, China). All mice were placed in an airconditioned room with a temperature of $24^{\circ} \mathrm{C}$ and a light cycle of $12 \mathrm{~h}$ and were provided with free feeding standard laboratory water and food. All animal experiments have been approved by the Animal Protection and Use Committee of Henan University of Science and Technology. 40 mice were randomly divided into Control group, Model group, ADSCs group and ADSCs + Mel group, with 10 mice in each group. For chronic $\mathrm{CCl}_{4}$-induced liver fibrosis, Model group, ADSCs group and ADSCs + Mel group mice were intraperitoneally injected with $8 \% \mathrm{CCl}_{4}$ solution at $1 \mathrm{ml} / \mathrm{kg}$ body weight $\left(\mathrm{CCl}_{4}\right.$ :oil $\left.=8: 92\right)$ and the control group was injected with the same dose of PBS twice a week for 4 weeks to induce liver fibrosis. At the beginning of week 5 , ADSCs group and ADSCs + Mel group mice were injected with $1 \times 10^{6} \mathrm{cells} / 1 \mathrm{ml}$ PBS dose of ADSCs and $50 \mu \mathrm{M}$ Mel pretreated ADSCs into tail vein, respectively, twice a week for 2 weeks. The mice in the model group and the control group were injected with the same dose of PBS in the tail vein.

\subsection{Biochemical Assays}

Blood was extracted from the heart immediately after the mice was sacrificed, and the serum was separated at $4{ }^{\circ} \mathrm{C}, 3500 \mathrm{rpm}$ for $10 \mathrm{~min}$, and stored at $-20^{\circ} \mathrm{C}$. The activities of ALT, AST, ALP, and ALB in 
the serum samples were measured using a commercial kit according to the operating instructions.

\subsection{Histopathological analysis}

After the liver tissue was fixed with $48 \mathrm{~h}$ of $4 \%$ polyformaldehyde, the tissue was dehydrated, embedded in paraffin, sectioned at $5 \mu \mathrm{m}$. The sections were stained with hematoxylin and eosin (H.E), and the histopathological changes were observed under microscope. Paraffin sections were also collected to perform immunohistochemistry and Masson's trichrome staining. Three representative sections were selected from each liver tissue and were detected in turn.

\subsection{Quantitative real-time reverse transcription PCR (RT- qPCR)}

Briefly, TRIzol (Cwbio Technologies, Beijing, China) reagent was used to extract total RNA from cryopreserved liver tissue when qRT-PCR analysis of liver tissue was performed. Next, cDNA reverse transcription was performed using the PrimeScript RT reagent kit (Takara, Dalian, China). The SYBR® Premix Ex Taq ${ }^{\text {TM }}$ kit (Takara, Dalian, China)was used for the next quantitative PCR assays. Target gene expression was quantified using the $2^{-\Delta \Delta}$ Ct method and normalized to the expression of GAPDH. The primer sequences are summarized in Table 1.

Table 1

Primer sequence.

\begin{tabular}{|c|c|c|}
\hline Gene & Forward primer ( $\left.5^{\prime}->3^{\prime}\right)$ & Reverse primer $\left(5^{\prime}->3^{\prime}\right)$ \\
\hline Caspase-3 & AGCTTGGAACGGTACGCTAA & GAGTCCACTGACTTGCTCCC \\
\hline Caspase-8 & GAAGGAACAGAAAAGGAACAGACT & GTAAGATGTCAGGTCATAGATGGAG \\
\hline Bcl-2 & CCATGATGGTTCTGATCAGCTC & GAACTCAAAGAAGGCCACAAC \\
\hline Bax & TTGCCCTCTTCTACTTTGCTAG & CCATGATGGTTCTGATCAGCTC \\
\hline$\beta$-actin & СTACСТСАTGAAGATСCTGACC & CACAGCTTCTCTTTGATGTCAC \\
\hline
\end{tabular}

According to the instructions, liver hydroxyproline (Hyp) levels are measured using a specific assay kit. Five replicates were used for each test.

\subsection{Immunohistochemical Staining and Assessment}

Before the immunohistochemical study, liver tissue sections were fixed with $4 \%$ paraformaldehyde for 48 $\mathrm{h}$, followed by tissue dehydration, paraffin embedding, and $5 \mu \mathrm{m}$ sections. After repair with $0.1 \mathrm{~mol} / \mathrm{L}$ antigenic repair solution, $3 \% \mathrm{H}_{2} \mathrm{O}_{2}$ was used for inactivation of endogenous enzymes, followed by $5 \% \mathrm{BSA}$ sealant. Primary antibody (TGF- $\beta$, 1:400 dilution), (MMP-9, 1:800 dilution), (MMP-2, 1:200 dilution) were incubated overnight at $4^{\circ} \mathrm{C}$. Goat anti-rabbit/mouse HRP labeled polymers were used as secondary antibodies, $37^{\circ} \mathrm{C}$ for $30 \mathrm{~min}$. After dehydration, the tissue was sealed with neutral gum and observed under 
a Nikon Eclipse E100 microscope. The immunohistochemical results were measured by image $\mathrm{J}$ software for section optical density (IOD).

\subsection{Statistical Analysis}

According to SPSS 20.0 statistical software, the data were analyzed by LSD's (Least Significant Difference) post hoctest and one-way ANOVA. All the data were presented as means \pm SD. $P<0.05$ was considered statistically significant.

\section{Results}

\subsection{Serum biochemical analysis}

Serum ALT, AST, ALP and ALB levels were detected to observe the changes of liver function(Y. Liu et al., 2021). As shown in Fig. 1, it is obvious that the serum levels of AST, ALT and ALP in model group were significantly higher than that in the control group, while the level of ALB was opposite. After treatment with ADSCs, we found that compared with the model group, the AST, ALT, and ALP activities of serum in ADSCs group and ADSCs + Mel group mice were significantly reduced, and ALB levels were significantly increased. Notably, the changes in ADSCs + Mel group are more significant. The above results indicate that Mel-incubated ADSCs are more helpful in improving liver injury induced by $\mathrm{CCl}_{4}$.

\subsection{Mel-incubated ADSCs improves $\mathrm{CCl}_{4}$-induced liver pathological changes}

The liver tissue was stained with H\&E for histopathological analysis. The hepatic sinusoids and hepatocytes of the control mice were arranged radially around the central vein with intact structure, large and round nuclei (Fig. 2). Compared with the above, unclear outlines, disordered arrangement, severe cytoplasmic vacuolation, fragmented nuclei were found in the model group (Fig. 2). After treatment with ADSCs, liver morphology improved significantly. And we found that ADSCs incubated with Mel improved better than the ADSCs group. The above results indicated that the Mel-incubated ADSCs had a better effect on the pathological changes of mice liver induced by $\mathrm{CCl}_{4}$.

\subsection{Mel-incubated ADSCs improves $\mathrm{CCl}_{4}$-induced liver fibrosis}

In order to explore the effect of Mel-incubated ADSCs on liver fibrosis, Masson staining and detection of Hyp content were used to reflect the content of collagen fibers in the liver of each group. Collagen fibers are dyed green. As shown in Fig. 3, compared with the control group, the green area and Hyp content of the model group were significantly increased, indicating that the liver had obvious fibrosis. After 2 weeks of treatment of ADSCs, the fibrosis area and Hyp content were significantly reduced. It was noted that compared with the ADSCs group, the Mel-incubated ADSCs had a better effect in reducing collagen fibers. 
The above results indicated that the Mel-incubated ADSCs had a better therapeutic effect on $\mathrm{CCl}_{4}$-induced liver fibrosis in mice.

\subsection{Mel-incubated ADSCs improves $\mathrm{CCl}_{4}$-induced hepatocyte apoptosis}

The Bcl-2 and Caspase families play an indispensable role in the execution and regulation of apoptosis(Y. Liu et al., 2021). The expression levels of protease caspase-8, Bax and caspase-3, anti-apoptotic gene Bcl2, pro-apoptotic gene Bax in each group were detected by qPCR. As shown in Fig. 4, compared with the control group, the expression levels of Bcl-2 were significantly reduced, and the expression levels of Caspase-8, Bax and Caspase -3 in the model group were significantly increased. After treatment of ADSCs, the expression levels of $\mathrm{Bcl}-2$ were significantly increased, and the expression levels of Caspase-8, Bax and Caspase-3 were significantly decreased. Notably, the changes in ADSCs + Mel group are more significant. The above results indicated that the Mel-incubated ADSCs had a better therapeutic effect on $\mathrm{CCl}_{4}$-induced hepatocyte apoptosis.

\subsection{Mel-incubated ADSCs regulated the expression of MMP- 9, TGF- $\beta$ and MMP-2 in liver injury.}

The occurrence of liver fibrosis is mainly caused by excessive synthesis or reduced degradation of extracellular matrix, and MMP-9, TGF- $\beta$ and MMP-2 play a crucial role in the synthesis and degradation of extracellular matrix(Beljaars, Daliri, Dijkhuizen, Poelstra, \& Gosens, 2017; Helaly, 2011; Kurzepa et al., 2014; Mohseni, Karimi, Tavilani, Khodadadi, \& Hashemnia, 2019). Therefore, the immunohistochemical results (expression of MMP-9, TGF- $\beta$ and MMP-2) of the sections were further observed under a microscope, and the optical density (IOD) values were measured and analyzed using Image $J$ software. As shown in Fig. 5-7, the number of MMP-9, TGF- $\beta$ and MMP-2 positive cells in the liver of mice in the control group was low, while a large number of yellow staining positive cells were found in the model group. The number of MMP-9, TGF- $\beta$ and MMP-2 positive cells in ADSCs alone group and ADSCs combined with Mel group were significantly decreased, and the number of positive cells decreased more in Mel combined with ADSCs group.

\section{Discussion}

The liver will be affected by harmful factors from the outside or inside the body and be damaged to varying degrees, so that it forms liver related diseases and then affect normal activities. So far, the clinical treatment methods for liver diseases are divided into drug therapy(Lambrecht, van Grunsven, \& Tacke, 2020) and liver transplantation(Aehling, Seehofer, \& Berg, 2020). On the one hand, traditional drugs can be effective in treating liver diseases. For example, statins, acetaminophen, flavonoids and other traditional Chinese medicine extracts can reduce liver fibrosis through anti-inflammatory, antioxidative stress and a series of pathways (NF-Kb, MAPK), which can effectively prevent liver injury in the 
process of chronic liver injury and play a role in protecting the liver(Fisher \& Curry, 2019; Jiang et al., 2019; Vargas, Arrese, Shah, \& Arab, 2017). However, the unreasonable use of drugs will produce side effects, for example, $7 \%-29 \%$ of patients will develop myotoxemia due to their own reasons and the unreasonable use of statins, the excessive use of acetaminophen will cause a series of pathological phenomena (such as vacuolar degeneration, hepatic lobular necrosis and hemorrhage) leading to liver failure, and the adverse reactions of flavonoids and Chinese medicine saponins will also cause liver toxicity(Cai, Qiu, Qi, \& Zhang, 2019; Cassidy \& Minihane, 2017; du Souich, Roederer, \& Dufour, 2017; Fisher \& Curry, 2019; X. Li, Li, Huang, Liu, \& Sun, 2018; Mahmoud \& Mahmoud, 2016; Wu et al., 2016). On the other hand, liver transplantation is also a means of clinical treatment of liver disease. Up to now, there have been one million cases of liver transplantation around the world, and the first-year survival rate for liver transplant patients is already as high as $\mathbf{8 0 - 9 0 \% ( M e i r e l l e s ~ J u ́ n i o r ~ e t ~ a l . , ~ 2 0 1 5 ) . ~ L i v e r ~ t r a n s p l a n t a t i o n ~ i s ~ s t i l l ~ l i m i t e d ~}$ due to factors such as limited liver sources, mismatches (rejection), and the mortality rate from liver transplantation remains high over time(Fukazawa \& Nishida, 2016; Kirchner, Goldaracena, Sapisochin, Alejandro, \& Shah, 2020). For example, long-term immunosuppression of liver transplant recipients may lead to complications such as infection, renal failure and malignant tumors, leading to long-term poor prognosis after treatment, and even liver injury caused by chronic immunity may also affect graft function(Jadlowiec \& Taner, 2016). According to the Spanish liver transplant registry a gradual decrease in 1, 5 and 10 year survival rates were $86 \%, 73 \%$ and $62 \%$, respectively(Pons Miñano, 2018). Oscar et al. performed 305 liver transplants on 284 patients and found that survival rates after 1 year and 5 years were $78 \%$ and $68 \%$, respectively. $30 \%$ of patients developed acute rejection, $41 \%$ found infection, and $14.5 \%$ had biliary tract complications(Santos et al., 2015). However, the study found that the intrahepatic transplantation of stem cells can change the immune regulation in the liver microenvironment(Regmi et al., 2019) and reduce the inflammatory damage of liver diseases(Chen et al., 2017), which has become a research object in the treatment of liver diseases in recent years. For example, due to the abnormal activation and proliferation of hematopoietic stem cells leading to liver fibrosis, ADSCs can promote the expression of HGF in the liver, prevent the expression of a-SMA, inhibit the proliferation of HSCs, promote the apoptosis of HSCs, and thereby alleviate liver fibrosis(W. P. Tang, Hu, Dai, He, \& Luo, 2018). Yan et al. pointed out that stem cell transplantation can change the migration of MDSCs, CD4 ${ }^{+} \mathrm{T}$ cells and the expression of immune cytokines to prevent acute liver injury caused by $\mathrm{ConA}(\mathrm{Bi}, \mathrm{Li}$, et al., 2019). Recently, a study using ADSCs of mesenteric origin to treat $\mathrm{CCl}_{4}$-induced liver cirrhosis in rats for 5 weeks found that ADSCs could improve the histopathological changes of the liver, and also make the rats have normal clinical behavior(Nazhvani, Haghani, Nazhvani, Namazi, \& Ghaderi, 2020). With the same results, based on liver function, biochemical and pathological tests, we concluded that ADSCs transplantation improved $\mathrm{CCl}_{4}$-induced hepatic fibrosis injury.

Cells of adult organs can be replaced by differentiation or transdifferentiation of stem cells, especially after injury(Kopp, Grompe, \& Sander, 2016). MSCs either lack the expression of class II major histocompatibility $(\mathrm{MHC})$ antigens or many molecules $(\mathrm{CD} 80, \mathrm{CD} 40, \mathrm{CD} 86 \mathrm{~N})$ required for immune recognition(Alfaifi, Eom, Newsome, \& Baik, 2018), so low immunogenicity is used by many investigators in experiments. It is known that stem cells or specially differentiated cells transplanted to the site of liver 
injury can differentiate or transdifferentiate under the influence of cytokines released by various cells, and differentiated liver cells or other cells can provide support for the liver and promote liver tissue repair(Bandi, Tchaikovskaya, \& Gupta, 2019; Ghosheh et al., 2017). Lay et al. found that human pluripotent stem cells (HPSC) differentiated into hepatocyte progenitor cells at day 6 and hepatocellular like cells at day 18 ,and they further showed that HPSC derived hepatocellular like cells were transplanted into liver injury model mice and migrated to the injury site, improving liver function and promoting the survival rate of mice(Ang et al., 2018; Loh, Palaria, \& Ang, 2019). Gage et al. showed that human pluripotent stem cells (HPSCs) could differentiate into venous angioblasts in vitro, which up-regulated the markers of hepatic sinusoid endothelial cells (LSEC), and produced mature LSEC after intrahepatic transplantation of LSEC in neonatal mice and adult mice(Gage et al., 2020). In addition, paracrine factors (cytokines, growth factors, exosomes, etc.) of stem cells can promote indirect and remote liver tissue repair by indirectly mediating anti-apoptosis, regulating nutritional factors, anti-fibrosis, anti-oxidation, angiogenesis, and immunosuppression(Watanabe et al., 2019). For example, stem cell-derived extracellular vesicles accumulate mainly in the liver, kidney, spleen, and lung, and that extracellular vesicles can reduce liver and kidney injury by reducing hepatic stellate cell activation and liver fibrosis or by treating mitochondrial injury through the mitochondrial transcription factor A (TFAM) pathway(Povero et al., 2019). Exosomes released into the extracellular environment by mesenchymal stem cells can be absorbed by target cells in the microenvironment, or can be carried far away through biological fluids, and inhibit hepatic stellate cell (HSC) activation through the Wnt/ $\beta$-catenin pathway, thereby modulating oxidative markers (MDA) and liver function markers(Hyp)and improving $\mathrm{CCl}_{4}$-induced liver fibrosis (Lou, Chen, Zheng, \& Liu, 2017; Rong et al., 2019). Su et al. showed that milk fat globules -EGF factor 8 (MFGE8), an anti-fibrotic protein in the MSC-secreted group and a potent inhibitor of HSC activation, strongly inhibited TGF- $\beta$ signaling and reduced extracellular matrix deposition and liver fibrosis in mice(An et al., 2017).

However, stem cell transplantation also has some problems, such as cell viability, differentiation and survival barrier at the damaged site after transplantation, which makes the transplantation efficiency not ideal(Kim, Na, Lee, Kim, \& Cho, 2015). Adrien et al. showed that the energy needed by the stem cells is produced by glucose fermentation, and that the stem cells die within three days of implantation when the damaged tissue area becomes too close to hypoxia $\left(0.1 \% \mathrm{O}_{2}\right)$ to produce energy and the body's energy reserves are used up(Moya et al., 2018). It has been reported that cell necrosis and apoptosis may occur due to the loss of adhesion related signals in most transplanted cells during the treatment with stem cells(Don \& Murry, 2013). Other studies have shown that ROS normally controls the signal transduction mechanism of the transplanted stem cells, but under pathological conditions, tissue damage will produce a large amount of ROS, which will harm the survival of stem cells(Kränkel, Spinetti, Amadesi, \& Madeddu, 2011). In 2010, a study showed that one hour after treating ischemic injury with stem cells, less than $1 \%$ of the cells in the injured kidney were detected and disappeared within a few days of injection(Burst et al., 2010). As research continues, it was reported in 2019 that within a week of transplantation, more than $80-90 \%$ of the stem cells die, leaving $9-19 \%$ of the cells in the animal(Zhao, Hu, Zhang, Jiang, \& Chen, 2019). Although transplant survival rates have improved, they are still not enough to meet demand, and 
more research is needed. Therefore, overcoming these obstacles is the key to stem cell transplantation in the treatment of liver disease.

Mel has been used by many researchers to improve the efficiency of stem cell proliferation, differentiation and transplantation in clinical experiments, due to its anti-inflammatory, anti-aging, anti-oxidation, antiapoptosis and other properties. For example, some scholars have found that melatonin can promote the proliferation and osteogenic differentiation of neural stem cells through PI3K/Akt signaling pathway in vitro(C. Liu et al., 2020; Yu, Zhang, Xu, \& Hu, 2019). Liu et al. induced oxidative damage of stem cells by $\mathrm{H}_{2} \mathrm{O}_{2}$ and $\mathrm{Ti}$ in vitro respectively, and found that Mel treatment not only significantly promoted the proliferation ability of ADSCs, but also improved the osteogenic differentiation ability of BMSCs through SIRT1 / SOD2 signaling pathway(Liao et al., 2020; Y. Zhang et al., 2020). Mel also has a protective effect on the aging of BMSCs induced by iron overload, because it can promote the proliferation of BMSCs, reduce the storage of ROS and the expression of ERK/p53/p38(Yang et al., 2017). In addition, there is literature showing that Mel can also reduce the aging and improve the survival rate of ADSCs by inhibiting the NF-kB signaling pathway(Fang et al., 2018), enhancing mitochondrial function(Lee, Yoon, Song, Noh, \& Lee, 2020). In treating the disease, Saberi et al. transplanted Mel-pretreated BMSCs into damaged kidneys and found that they reduced renal fibrosis, improved the condition of the damaged renal tubule tissue, and significantly increased cell transplant survival(Saberi et al., 2019). Li et al. demonstrated that Mel-pretreated MSC enhanced mitochondrial Mel and cell cyclin-related protein activity by increasing the expression of peroxidase-associated receptor PGC-1a, significantly increased the survival rate of MSC, promoted the formation of new blood vessels and decreased fibrosis, and improved the ischemic tissue of limbs(Lee, Han, \& Lee, 2020). In the treatment of $\mathrm{CCl}_{4}$-induced hepatic fibrosis, Mel pretreated BMSCs decreased the expression of Bax and TGF- $\beta 1$, decreased the serum ALT content, but increased the expression of Bcl2 and MMPs, compared with BMSCs alone(K. Mortezaee et al., 2017). Similarly, Data showed that pretreatment of ADSCs with $10 \mu \mathrm{M}$ Mel $(1 \mathrm{mM})$ in medium increased transplantation efficiency, decreased AST, ALT, TBIL, hepatic hydroxyproline expression and hepatic fibrosis area, and improved $\mathrm{CCl}_{4}$-induced liver injury(Liao et al., 2020). According to our previous study, 50 $\mu \mathrm{M} M T$ at different concentrations significantly promoted the proliferative activity of ADSCs, so we used $50 \mu \mathrm{M}$ MT pretreated ADSCs in the treatment of $\mathrm{CCl}_{4}$-induced liver fibrosis. The results showed that ADSCs pretreated with $50 \mu \mathrm{M}$ MT significantly improved liver function, liver pathology, and apoptotic genes compared with ADSCs alone.

The synthesis and degradation of extracellular matrix (ECM) are in dynamic equilibrium in normal liver. When the liver is damaged, this equilibrium is disrupted, leading to the activation of fibrosis matrix metalloproteinases (MMPs), which are responsible for the turnover of ECM during highly dynamic processes(Bi, Liu, et al., 2019). In addition, it has been reported that with the progression of fibrosis, the acute phase will lead to increased expression of matrix metalloproteinases (MMPs) and tissue inhibitors (TIMPs) in the liver(Arthur, 2000). However, the expression of MMP-2 and MMP-9 is considered as an early signal of hepatotoxin and hepatitis response(Hernandez-Gea \& Friedman, 2011). Studies have also shown that fibrosis will lead to the abnormal activation and proliferation of hematopoietic stem cells 
(HSCs), and the decomposition of type IV collagen by activated MMP-2 is a necessary condition for HSCs to maintain physiological static state(Ma et al., 2019). Activated HSCs are also considered to be the primary source of MMP-2 in the liver, which in turn promotes the activation of HSCs by degrading the normal subcutaneous matrix and disrupting the environment of HSCs and other cells(Ma et al., 2019). Therefore, the production of MMP-2 interacts with the activation of HSCs. Like MMP-2, activated MMP-9 also degrades type IV collagen, which in turn promotes the activation of HSCs and Kupffer cells, which secrete large amounts of TIMPs, type I, and type III collagen(Wang et al., 2019; Xu, Liu, Fang, Gao, \& Yan, 2014). For example, the study of Long et al. showed that $\mathrm{CCl}_{4}$-induced liver injury can significantly increase the expression of MMP-2 and MMP-9, while trans-2,3,5,4'-tetrahydroxystilbene 2-O- $\beta-D-$ glucopyranoside (Trans-THSG) significantly reduced this change(Long et al., 2019). Artesunate has also been shown to improve bovine serum albumin-induced liver fibrosis in rats by decreasing MMP2, a-SMA, and MMP-9(Xu et al., 2014). During the development of liver fibrosis, some endogenous pro-fibrogenic factors such as IL-17 are released, which in turn This stimulated Kupffer cells to produce other proinflammatory factors (TGF- $\beta 1$ and TNF-a), all of which stimulate HSC activation to express collagen and enhance ECM deposition(Long et al., 2019). In addition, studies have shown that TGF- $\beta$ is activated through a variety of mechanisms, including MMP2 and MMP-9(Piek, Heldin, \& Ten Dijke, 1999). Li et al. also proved that Chinese medicine CGA formula can reduce the expressions of TGF- $\beta$, MMP2 and MMP-9 in the liver tissue of rats with DMN-induced liver fibrosis(X. M. Li et al., 2016). And again, our study found that MMP2, TGF- $\beta$ and MMP-9-positive cells were significantly expressed in the liver after administration of $\mathrm{CCl}_{4}$. These were significantly reduced by Mel-incubated ADSCs. It is suggested that reducing the expression of MMP2 and MMP-9 can improve the survival environment of HSCs and other cells, thereby reducing the activation of HSCs and improving the pathological changes of liver tissue. However, the role of MMP2 and MMP-9 remains controversial. Daniel et al. showed that MMP2 and MMP-9 were significantly expressed in rat liver fibrosis induced by diethylnitrosamine, while the treatment of S-Nitroso$\mathrm{N}$-acetylcysteine (SNAC) significantly reduced this change(Mazo et al., 2013). Conflicts may occur due to the existence of different types of animal models and very complex mechanisms leading to liver fibrosis. So the exploration of its mechanism may require further research.

\section{Conclusion}

In conclusion, $\mathrm{CCl}_{4}$-induced liver fibrosis was significantly improved by Mel-pretreated ADSCs, which provides a reference for clinical treatment of liver injury with mesenchymal stem cells.

\section{Declarations}

Ethical Approval: All animal care and procedures were performed in accordance with institutional and national guidelines and approved by the Institutional Animal Care and Use Committee of Henan University of Science and Technology (China) (No.20190619024). All works were conducted according to the ARRIVE guidelines.

Consent to Participate: The final manuscript was read and approved by all authors. 
Consent to Publish: All authors read it and agreed to publish it.

Authors Contributions: HJ Wang, YX Yang, RQ Dong, YL Xu, MY Zhang performed the experiments. QX Lv and XG Chen analyzed the data. YY Sun and HJ Wang prepared the manuscript. YM Liu and YY Sun the revision of the manuscript. ZQ Zhang Ang YM Liu proposed the concept of the study and directed the design and implementation of the study.

Funding: The National Natural Science Foundation of China (Grant No. U1504325) and the Foundation of Henan Province (Grant No.31101779).

Competing Interests: The authors declare that they have no competing interests or declaration.

Availability of data and materials: The data underlying this article will be shared on reasonable request to the corresponding author.

\section{References}

Aehling, N. F., Seehofer, D., \& Berg, T. (2020). [Liver transplantation - current trends]. Dtsch Med Wochenschr, 145(16), 1124-1131. doi:10.1055/a-0982-0737

Alfaifi, M., Eom, Y. W., Newsome, P. N., \& Baik, S. K. (2018). Mesenchymal stromal cell therapy for liver diseases. J Hepatol, 68(6), 1272-1285. doi:10.1016/j.jhep.2018.01.030

An, S. Y., Jang, Y. J., Lim, H. J., Han, J., Lee, J., Lee, G., . . Kim, J. H. (2017). Milk Fat Globule-EGF Factor 8, Secreted by Mesenchymal Stem Cells, Protects Against Liver Fibrosis in Mice. Gastroenterology, 152(5), 1174-1186. doi:10.1053/j.gastro.2016.12.003

Ang, L. T., Tan, A. K. Y., Autio, M. I., Goh, S. H., Choo, S. H., Lee, K. L., . . Lim, B. (2018). A Roadmap for Human Liver Differentiation from Pluripotent Stem Cells. Cell Rep, 22(8), 2190-2205.

doi:10.1016/j.celrep.2018.01.087

Arthur, M. J. (2000). Fibrogenesis II. Metalloproteinases and their inhibitors in liver fibrosis. Am J Physiol Gastrointest Liver Physiol, 279(2), G245-249. doi:10.1152/ajpgi.2000.279.2.G245

Aydın, M. M., \& Akçalı, K. C. (2018). Liver fibrosis. Turk J Gastroenterol, 29(1), 14-21. doi:10.5152/tjg.2018.17330

Banas, A., Teratani, T., Yamamoto, Y., Tokuhara, M., Ochiya, T., \& Hepatology. (2008). Rapid hepatic fate specification of adipose-derived stem cells and their therapeutic potential for liver failure. Journal of Gastroenterology, 24(1), 70-77.

Bandi, S., Tchaikovskaya, T., \& Gupta, S. (2019). Hepatic differentiation of human pluripotent stem cells by developmental stage-related metabolomics products. Differentiation, 105, 54-70.

doi:10.1016/j.diff.2019.01.005

Page 12/25 
Beljaars, L., Daliri, S., Dijkhuizen, C., Poelstra, K., \& Gosens, R. (2017). WNT-5A regulates TGF- $\beta$-related activities in liver fibrosis. Am J Physiol Gastrointest Liver Physiol, 312(3), G219-g227.

doi:10.1152/ajpgi.00160.2016

Bi, Y., Li, J., Yang, Y., Wang, Q., Wang, Q., Zhang, X., . . Hong, F. (2019). Human liver stem cells attenuate concanavalin A-induced acute liver injury by modulating myeloid-derived suppressor cells and CD4(+) T cells in mice. Stem Cell Res Ther, 10(1), 22. doi:10.1186/s13287-018-1128-2

Bi, Y., Liu, X., Si, C., Hong, Y., Lu, Y., Gao, P., . . Hong, F. (2019). Transplanted adult human hepatic stem/progenitor cells prevent histogenesis of advanced hepatic fibrosis in mice induced by carbon tetrachloride. Am J Transl Res, 11(4), 2350-2358.

Burst, V. R., Gillis, M., Pütsch, F., Herzog, R., Fischer, J. H., Heid, P., . . Benzing, T. (2010). Poor cell survival limits the beneficial impact of mesenchymal stem cell transplantation on acute kidney injury. Nephron Exp Nephrol, 114(3), e107-116. doi:10.1159/000262318

Cai, P., Qiu, H., Qi, F., \& Zhang, X. (2019). The toxicity and safety of traditional Chinese medicines: Please treat with rationality. Biosci Trends, 13(5), 367-373. doi:10.5582/bst.2019.01244

Cassidy, A., \& Minihane, A. M. (2017). The role of metabolism (and the microbiome) in defining the clinical efficacy of dietary flavonoids. Am J Clin Nutr, 105(1), 10-22. doi:10.3945/ajcn.116.136051

Chen, D., Li, Q., Meng, Z., Guo, L., Tang, Y., Liu, Z., . . Wu, C. (2017). Bright Polymer Dots Tracking Stem Cell Engraftment and Migration to Injured Mouse Liver. Theranostics, 7(7), 1820-1834.

doi:10.7150/thno. 18614

Cho, Y. A., Noh, K., Jue, S. S., Lee, S. Y., \& Kim, E. C. (2015). Melatonin promotes hepatic differentiation of human dental pulp stem cells: clinical implications for the prevention of liver fibrosis. Journal of Pineal Research, 58(1), 127-135.

Don, C. W., \& Murry, C. E. (2013). Improving survival and efficacy of pluripotent stem cell-derived cardiac grafts. J Cell Mol Med, 17(11), 1355-1362. doi:10.1111/jcmm.12147

du Souich, P., Roederer, G., \& Dufour, R. (2017). Myotoxicity of statins: Mechanism of action. Pharmacol Ther, 175, 1-16. doi:10.1016/j.pharmthera.2017.02.029

Eom, Y. W., Shim, K. Y., \& Baik, S. K. (2015). Mesenchymal stem cell therapy for liver fibrosis. Korean J Intern Med, 30(5), 580-589. doi:10.3904/kjim.2015.30.5.580

Fallowfield, J. A., \& Iredale, J. P. (2004). Targeted treatments for cirrhosis. Expert Opinion on Therapeutic Targets, 8(5), 423-435.

Fang, J., Yan, Y., Teng, X., Wen, X., Li, N., Peng, S., . . Hua, J. (2018). Melatonin prevents senescence of canine adipose-derived mesenchymal stem cells through activating NRF2 and inhibiting ER stress. Aging 
Fisher, E. S., \& Curry, S. C. (2019). Evaluation and treatment of acetaminophen toxicity. Adv Pharmacol, 85, 263-272. doi:10.1016/bs.apha.2018.12.004

Fu, J., Zhao, S. D., Liu, H. J., Yuan, Q. H., Liu, S. M., Zhang, Y. M., . . Hao, A. J. (2011). Melatonin promotes proliferation and differentiation of neural stem cells subjected to hypoxia in vitro. J Pineal Res, 51(1), 104-112. doi:10.1111/j.1600-079X.2011.00867.x

Fukazawa, K., \& Nishida, S. (2016). Size mismatch in liver transplantation. J Hepatobiliary Pancreat Sci, 23(8), 457-466. doi:10.1002/jhbp.371

Gage, B. K., Liu, J. C., Innes, B. T., MacParland, S. A., McGilvray, I. D., Bader, G. D., \& Keller, G. M. (2020). Generation of Functional Liver Sinusoidal Endothelial Cells from Human Pluripotent Stem-Cell-Derived Venous Angioblasts. Cell Stem Cell, 27(2), 254-269.e259. doi:10.1016/j.stem.2020.06.007

Ghosheh, N., Küppers-Munther, B., Asplund, A., Edsbagge, J., Ulfenborg, B., Andersson, T. B., . . . Synnergren, J. (2017). Comparative transcriptomics of hepatic differentiation of human pluripotent stem cells and adult human liver tissue. Physiol Genomics, 49(8), 430-446.

doi:10.1152/physiolgenomics.00007.2017

Helaly, G. F. (2011). Differences in circulating MMP-9 levels with regard to viral load and AST:ALT ratio between chronic hepatitis B and C patients. Br J Biomed Sci, 68(1), 38-42.

doi:10.1080/09674845.2011.11732840

Hernandez-Gea, V., \& Friedman, S. L. (2011). Pathogenesis of liver fibrosis. Annu Rev Pathol, 6, 425-456. doi:10.1146/annurev-pathol-011110-130246

Jadlowiec, C. C., \& Taner, T. (2016). Liver transplantation: Current status and challenges. World J Gastroenterol, 22(18), 4438-4445. doi:10.3748/wjg.v22.i18.4438

Jiang, J., Yan, L., Shi, Z., Wang, L., Shan, L., \& Efferth, T. (2019). Hepatoprotective and anti-inflammatory effects of total flavonoids of Qu Zhi Ke (peel of Citrus changshan-huyou) on non-alcoholic fatty liver disease in rats via modulation of NF-KB and MAPKs. Phytomedicine, 64, 153082.

doi:10.1016/j.phymed.2019.153082

Jiaqi, Chu, Yalin, Tu, Jingkao, Chen, .. . Liu. (2016). Effects of melatonin and its analogues on neural stem cells. Molecular Cellular Endocrinology.

Kia, R., Sison, R. L. C., Heslop, J., Kitteringham, N. R., Hanley, N., Mills, J. S., .. Goldring, C. E. P. (2013). Stem cell-derived hepatocytes as a predictive model for drug-induced liver injury: are we there yet? British Journal of Clinical Pharmacology, 75(4), 885-896. 
Kim, P. H., Na, S. S., Lee, B., Kim, J. H., \& Cho, J. Y. (2015). Stanniocalcin 2 enhances mesenchymal stem cell survival by suppressing oxidative stress. BMB Rep, 48(12), 702-707.

doi:10.5483/bmbrep.2015.48.12.158

Kirchner, V. A., Goldaracena, N., Sapisochin, G., Alejandro, R. H., \& Shah, S. A. (2020). Current status of liver transplantation in North America. Int J Surg, 82s, 9-13. doi:10.1016/j.ijsu.2020.05.059

Kopp, J. L., Grompe, M., \& Sander, M. (2016). Stem cells versus plasticity in liver and pancreas regeneration. Nat Cell Biol, 18(3), 238-245. doi:10.1038/ncb3309

Kränkel, N., Spinetti, G., Amadesi, S., \& Madeddu, P. (2011). Targeting stem cell niches and trafficking for cardiovascular therapy. Pharmacol Ther, 129(1), 62-81. doi:10.1016/j.pharmthera.2010.10.002

Kumar, A., Kumar, K., Singh, R., Puri, G., Ranjan, R., Yasotha, T., . . Bag, S. (2012). Effect of mitotic inducers and retinoic acid blocker on expression of pluripotent genes in ES cells derived from early stage in vitro-produced embryos in buffalo. Vitro Cellular Developmental Biology Animal, 48(10), 625-632.

Kung, J. W., \& Forbes, S. J. (2009). Stem cells and liver repair. Current Opinion in Biotechnology, 20(5), 568-574.

Kurzepa, J., Mądro, A., Czechowska, G., Kurzepa, J., Celiński, K., Kazmierak, W., \& Slomka, M. (2014). Role of MMP-2 and MMP-9 and their natural inhibitors in liver fibrosis, chronic pancreatitis and non-specific inflammatory bowel diseases. Hepatobiliary Pancreat Dis Int, 13(6), 570-579. doi:10.1016/s14993872(14)60261-7

Lambrecht, J., van Grunsven, L. A., \& Tacke, F. (2020). Current and emerging pharmacotherapeutic interventions for the treatment of liver fibrosis. Expert Opin Pharmacother, 21(13), 1637-1650. doi:10.1080/14656566.2020.1774553

Lee, J. H., Han, Y. S., \& Lee, S. H. (2020). Melatonin-Induced PGC-1a Improves Angiogenic Potential of Mesenchymal Stem Cells in Hindlimb Ischemia. Biomol Ther (Seoul), 28(3), 240-249. doi:10.4062/biomolther.2019.131

Lee, J. H., Yoon, Y. M., Song, K. H., Noh, H., \& Lee, S. H. (2020). Melatonin suppresses senescence-derived mitochondrial dysfunction in mesenchymal stem cells via the HSPA1L-mitophagy pathway. Aging Cell, 19(3), e13111. doi:10.1111/acel.13111

Li, X., Li, X., Huang, N., Liu, R., \& Sun, R. (2018). A comprehensive review and perspectives on pharmacology and toxicology of saikosaponins. Phytomedicine, 50, 73-87.

doi:10.1016/j.phymed.2018.09.174

Li, X. M., Peng, J. H., Sun, Z. L., Tian, H. J., Duan, X. H., Liu, L., . . Hu, Y. Y. (2016). Chinese medicine CGA formula ameliorates DMN-induced liver fibrosis in rats via inhibiting MMP2/9, TIMP1/2 and the TGFB/Smad signaling pathways. Acta Pharmacol Sin, 37(6), 783-793. doi:10.1038/aps.2016.35 
Liao, N., Shi, Y., Wang, Y., Liao, F., Zhao, B., Zheng, Y., . . . Liu, J. (2020). Antioxidant preconditioning improves therapeutic outcomes of adipose tissue-derived mesenchymal stem cells through enhancing intrahepatic engraftment efficiency in a mouse liver fibrosis model. Stem Cell Res Ther, 11(1), 237. doi:10.1186/s13287-020-01763-y

Liu, C., Zhou, W., Li, Z., Ren, J., Li, X., Li, S., . . Wang, F. (2020). Melatonin Protects Neural Stem Cells Against Tri-Ortho-Cresyl Phosphate-Induced Autophagy. Front Mol Neurosci, 13, 25.

doi:10.3389/fnmol.2020.00025

Liu, Y., Wang, H., Zhang, M., Wang, J., Zhang, Z., Wang, Y., . . Zhang, Z. (2021). Protective effect of selenomethionine on T-2 toxin-induced liver injury in New Zealand rabbits. BMC Vet Res, 17(1), 153. doi:10.1186/s12917-021-02866-1

Loh, K. M., Palaria, A., \& Ang, L. T. (2019). Efficient Differentiation of Human Pluripotent Stem Cells into Liver Cells. J Vis Exp(148). doi:10.3791/58975

Long, T., Wang, L., Yang, Y., Yuan, L., Zhao, H., Chang, C. C., . . Li, S. (2019). Protective effects of trans2,3,5,4'-tetrahydroxystilbene 2-0- $\beta$-d-glucopyranoside on liver fibrosis and renal injury induced by $\mathrm{CCl}(4)$ via down-regulating $\mathrm{p}$-ERK1/2 and p-Smad1/2. Food Funct, 10(8), 5115-5123. doi:10.1039/c9fo01010f

Lou, G., Chen, Z., Zheng, M., \& Liu, Y. (2017). Mesenchymal stem cell-derived exosomes as a new therapeutic strategy for liver diseases. Exp Mol Med, 49(6), e346. doi:10.1038/emm.2017.63

Ma, J., Qiu, Y., Wang, M., Zhang, M., Zhao, X., \& Jiang, H. (2019). Locostatin Alleviates Liver Fibrosis Induced by Carbon Tetrachloride in Mice. Dig Dis Sci, 64(9), 2570-2580. doi:10.1007/s10620-019-05588-5

Mahmoud, Y. I., \& Mahmoud, A. A. (2016). Role of nicotinamide (vitamin B3) in acetaminophen-induced changes in rat liver: Nicotinamide effect in acetaminophen-damged liver. Exp Toxicol Pathol, 68(6), 345354. doi:10.1016/j.etp.2016.05.003

Margheri, M., Pacini, N., Tani, A., Nosi, D., Squecco, R., Dama, A., .. Formigli, L. (2012). Combined effects of melatonin and all-trans retinoic acid and somatostatin on breast cancer cell proliferation and death: Molecular basis for the anticancer effect of these molecules. European Journal of Pharmacology, 681(13), 34-43.

Mazo, D. F., de Oliveira, M. G., Pereira, I. V., Cogliati, B., Stefano, J. T., de Souza, G. F., . . de Oliveira, C. P. (2013). S-nitroso-N-acetylcysteine attenuates liver fibrosis in experimental nonalcoholic steatohepatitis. Drug Des Devel Ther, 7, 553-563. doi:10.2147/dddt.S43930

Meirelles Júnior, R. F., Salvalaggio, P., Rezende, M. B., Evangelista, A. S., Guardia, B. D., Matielo, C. E., . . Meira Filho, S. P. (2015). Liver transplantation: history, outcomes and perspectives. Einstein (Sao Paulo), 13(1), 149-152. doi:10.1590/s1679-45082015rw3164 
Mohseni, R., Karimi, J., Tavilani, H., Khodadadi, I., \& Hashemnia, M. (2019). Carvacrol ameliorates the progression of liver fibrosis through targeting of Hippo and TGF- $\beta$ signaling pathways in carbon tetrachloride (CCl(4))-induced liver fibrosis in rats. Immunopharmacol Immunotoxicol, 41(1), 163-171. doi:10.1080/08923973.2019.1566926

Mortezaee, K. (2018). Human hepatocellular carcinoma: Protection by melatonin. J Cell Physiol, 233(10), 6486-6508. doi:10.1002/jcp.26586

Mortezaee, K., \& Khanlarkhani, N. (2017). Melatonin application in targeting oxidative-induced liver injuries: a review. Journal of Cellular Physiology.

Mortezaee, K., Khanlarkhani, N., Sabbaghziarani, F., Nekoonam, S., Majidpoor, J., Hosseini, A., . . . Zendedel, A. (2017). Preconditioning with melatonin improves therapeutic outcomes of bone marrowderived mesenchymal stem cells in targeting liver fibrosis induced by CCl4. Cell Tissue Res, 369(2), 303312. doi:10.1007/s00441-017-2604-1

Moya, A., Paquet, J., Deschepper, M., Larochette, N., Oudina, K., Denoeud, C., . . Petite, H. (2018). Human Mesenchymal Stem Cell Failure to Adapt to Glucose Shortage and Rapidly Use Intracellular Energy Reserves Through Glycolysis Explains Poor Cell Survival After Implantation. Stem Cells, 36(3), 363-376. doi:10.1002/stem.2763

Nazhvani, F. D., Haghani, I., Nazhvani, S. D., Namazi, F., \& Ghaderi, A. (2020). Regenerative effect of mesenteric fat stem cells on ccl4-induced liver cirrhosis, an experimental study. Ann Med Surg (Lond), 60, 135-139. doi:10.1016/j.amsu.2020.10.045

Piek, E., Heldin, C. H., \& Ten Dijke, P. (1999). Specificity, diversity, and regulation in TGF-beta superfamily signaling. Faseb j, 13(15), 2105-2124.

Pons Miñano, J. A. (2018). Protecting renal function: a relevant decision for liver transplantation. Rev Esp Enferm Dig, 110(9), 535-537. doi:10.17235/reed.2018.5836/2018

Povero, D., Pinatel, E. M., Leszczynska, A., Goyal, N. P., Nishio, T., Kim, J., . . Feldstein, A. E. (2019). Human induced pluripotent stem cell-derived extracellular vesicles reduce hepatic stellate cell activation and liver fibrosis. JCl Insight, 5(14). doi:10.1172/jci.insight.125652

Regmi, S., Pathak, S., Thanh, T. P., Nguyen, T. T., Sung, J. H., Yook, S., . . Jeong, J. H. (2019). Intraportally delivered stem cell spheroids localize in the liver and protect hepatocytes against GaIN/LPS-induced fulminant hepatic toxicity. Stem Cell Res Ther, 10(1), 230. doi:10.1186/s13287-019-1337-3

Rong, X., Liu, J., Yao, X., Jiang, T., Wang, Y., \& Xie, F. (2019). Human bone marrow mesenchymal stem cells-derived exosomes alleviate liver fibrosis through the Wnt/ $\beta$-catenin pathway. Stem Cell Res Ther, 10(1), 98. doi:10.1186/s13287-019-1204-2 
Saberi, K., Pasbakhsh, P., Omidi, A., Borhani-Haghighi, M., Nekoonam, S., Omidi, N., . . Kashani, I. R. (2019). Melatonin preconditioning of bone marrow-derived mesenchymal stem cells promotes their engraftment and improves renal regeneration in a rat model of chronic kidney disease. $J$ Mol Histol, 50(2), 129-140. doi:10.1007/s10735-019-09812-4

Santos, O., Londoño, M., Marín, J., Muñoz, O., Mena, Á., Guzmán, C., . . Correa, G. (2015). An experience of liver transplantation in Latin America: a medical center in Colombia. Colomb Med (Cali), 46(1), 8-13.

Shibo, Lin, Katrin, Hoffmann, Chao, Gao, ... Herr. (2017). Melatonin promotes sorafenib-induced apoptosis through synergistic activation of JNK/c-jun pathway in human hepatocellular carcinoma. Journal of Pineal Research.

Shu, S. N., Wei, L., Wang, J. H., Zhan, Y. T., Chen, H. S., \& Wang, Y. (2004). Hepatic differentiation capability of rat bone marrow-derived mesenchymal stem cells and hematopoietic stem cells. World Journal of Gastroenterology, 10(19), 2818-2822.

Si-Tayeb, K., Noto, F. K., Nagaoka, M., Li, J., Battle, M. A., Duris, C., . . Duncan, S. A. (2010). Highly efficient generation of human hepatocyte-like cells from induced pluripotent stem cells. Hepatology, 51(1), 297305.

Strem, B. M., Hicok, K. C., Min, Z., Wulur, l., \& Hedrick, M. H. (2005). Multipotential differentiation of adipose tissue-derived stem cells. Keio Journal of Medicine, 54(3), 132-141.

Sun, M., \& Kisseleva, T. (2015). Reversibility of liver fibrosis. Clin Res Hepatol Gastroenterol, 39 Suppl 1(0 1), S60-63. doi:10.1016/j.clinre.2015.06.015

Tang, W. P., Hu, Q., Dai, X. M., He, G. S., \& Luo, J. X. (2018). [Effect of adipose tissue-derived mesenchymal stem cell transplantation in treatment of liver fibrosis and possible mechanism]. Zhonghua Gan Zang Bing Za Zhi, 26(1), 28-33. doi:10.3760/cma.j.issn.1007-3418.2018.01.008

Tang, Y., Cai, B., Yuan, F., He, X., Lin, X., Wang, J., . . Yang, G. Y. (2014). Melatonin Pretreatment Improves the Survival and Function of Transplanted Mesenchymal Stem Cells after Focal Cerebral Ischemia. Cell Transplantation, 23(10), 1279-1291.

Trefts, E., Gannon, M., \& Wasserman, D. H. (2017). The liver. Curr Biol, 27(21), R1147-r1151. doi:10.1016/j.cub.2017.09.019

Vargas, J. I., Arrese, M., Shah, V. H., \& Arab, J. P. (2017). Use of Statins in Patients with Chronic Liver Disease and Cirrhosis: Current Views and Prospects. Curr Gastroenterol Rep, 19(9), 43. doi:10.1007/s11894-017-0584-7

Wang, Q., Liu, X., Zhang, J., Lu, L., Feng, M., \& Wang, J. (2019). Dynamic features of liver fibrogenesis and fibrosis resolution in the absence of matrix metalloproteinase-9. Mol Med Rep, 20(6), 5239-5248. doi:10.3892/mmr.2019.10740 
Watanabe, Y., Tsuchiya, A., Seino, S., Kawata, Y., Kojima, Y., Ikarashi, S., . . Terai, S. (2019). Mesenchymal Stem Cells and Induced Bone Marrow-Derived Macrophages Synergistically Improve Liver Fibrosis in Mice. Stem Cells Trans/ Med, 8(3), 271-284. doi:10.1002/sctm.18-0105

Wu, H., Zhong, R. L., Xia, Z., Huang, H. C., Zhong, Q. X., Feng, L., . . Jia, X. B. (2016). [Research progress on potential liver toxic components in traditional Chinese medicine]. Zhongguo Zhong Yao Za Zhi, 41(17), 3209-3217. doi:10.4268/cjcmm20161715

Xu, Y., Liu, W., Fang, B., Gao, S., \& Yan, J. (2014). Artesunate ameliorates hepatic fibrosis induced by bovine serum albumin in rats through regulating matrix metalloproteinases. Eur J Pharmacol, 744, 1-9. doi:10.1016/j.ejphar.2014.09.035

Yang, F., Yang, L., Li, Y., Yan, G., Feng, C., Liu, T., . . Cai, B. (2017). Melatonin protects bone marrow mesenchymal stem cells against iron overload-induced aberrant differentiation and senescence. $J$ Pineal Res, 63(3). doi:10.1111/jpi.12422

Yu, S., Zhang, X., Xu, Z., \& Hu, C. (2019). Melatonin promotes proliferation of neural stem cells from adult mouse spinal cord via the PI3K/AKT signaling pathway. FEBS Lett, 593(14), 1751-1762.

doi:10.1002/1873-3468.13458

Zhang, Y., Zhu, X., Wang, G., Chen, L., Yang, H., He, F., \& Lin, J. (2020). Melatonin Rescues the Ti ParticleImpaired Osteogenic Potential of Bone Marrow Mesenchymal Stem Cells via the SIRT1/SOD2 Signaling Pathway. Calcif Tissue Int, 107(5), 474-488. doi:10.1007/s00223-020-00741-z

Zhang, Z., \& Wang, F. S. (2013). Stem cell therapies for liver failure and cirrhosis. Journal of Hepatology, 59(1), 183-185.

Zhao, L., Hu, C., Zhang, P., Jiang, H., \& Chen, J. (2019). Preconditioning strategies for improving the survival rate and paracrine ability of mesenchymal stem cells in acute kidney injury. J Cell Mol Med, 23(2), 720-730. doi:10.1111/jcmm. 14035

Zhou, W. C., Zhang, Q. B., \& Qiao, L. (2014). Pathogenesis of liver cirrhosis. World J Gastroenterol, 20(23), 7312-7324. doi:10.3748/wjg.v20.i23.7312

Zuk, P. A., Zhu, M., Mizuno, H., Huang, J., Futrell, J. W., Katz, A. J., . . Hedrick, M. H. (2001). Multilineage Cells from Human Adipose Tissue: Implications for Cell-Based Therapies. Tissue Engineering Part A, 7(2), 211-228.

\section{Figures}



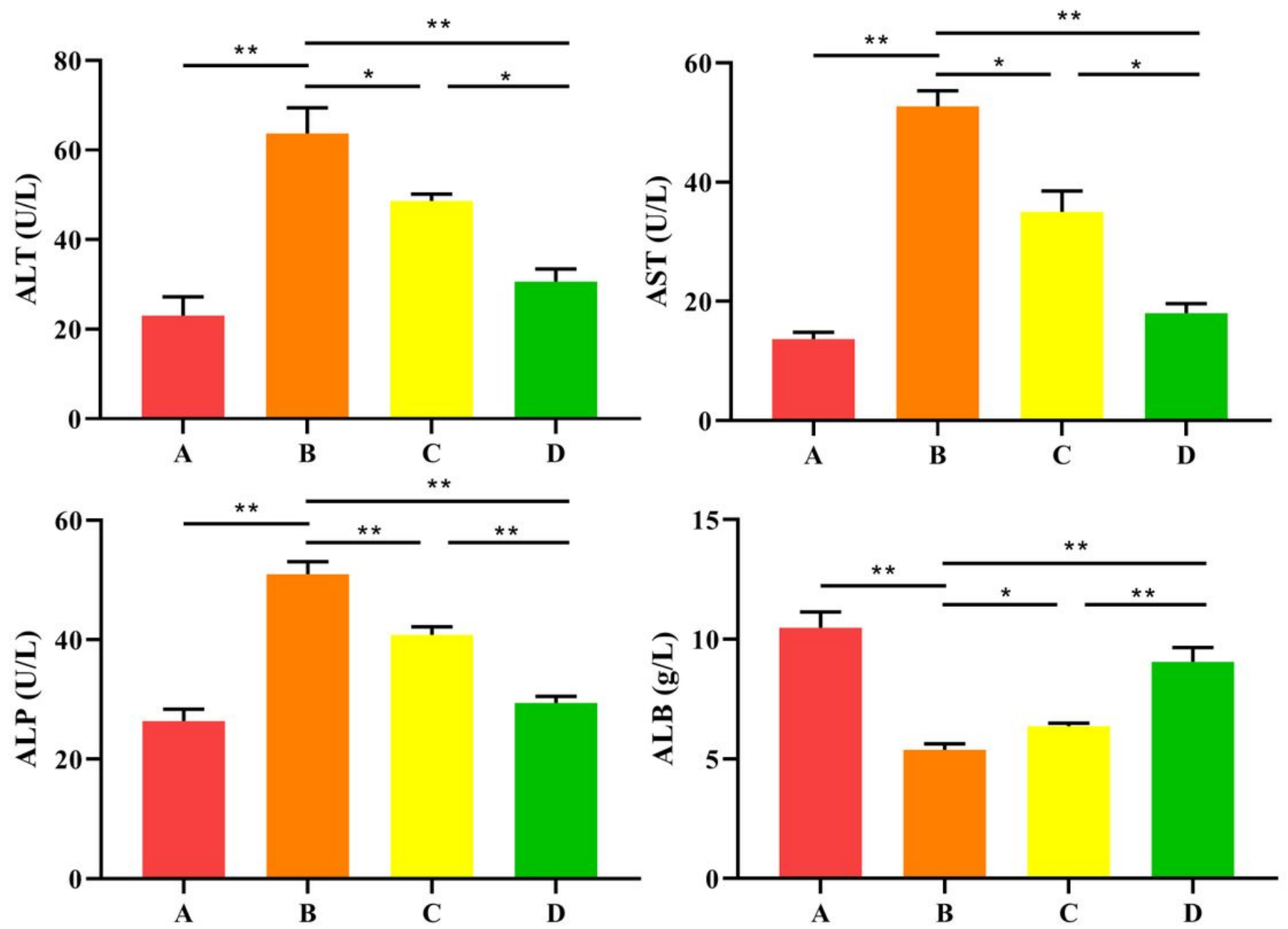

Figure 1

The effect of Mel-incubated ADSCs on CCl4-induced serum biochemical indices. A Control group. B Model group. C ADSCs treatment group. D ADSCs combined with Mel treatment group. Note: *indicates significant, $\mathrm{P}<0.05$; **indicates extremely significant, $\mathrm{P}<0.01$. 

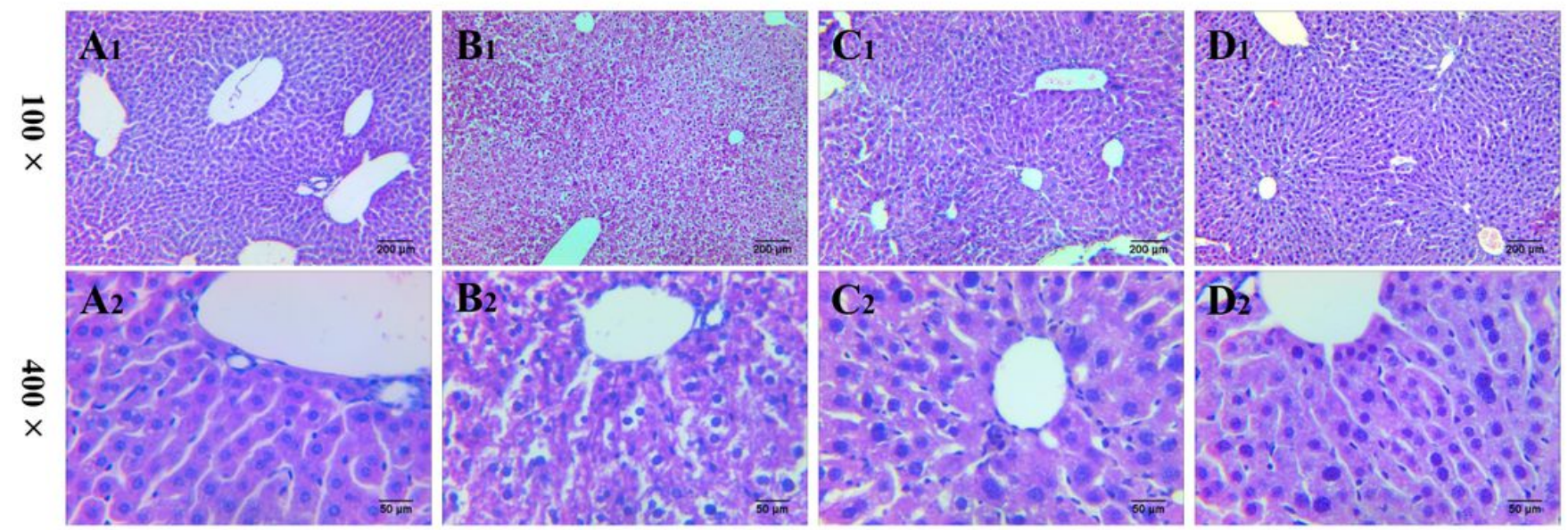

Figure 2

The effect of Mel-incubated ADSCs on CCl4-induced liver pathology. A1, A2 Control group. B1, B2 Model group. C1, C2 ADSCs treatment group. D1, D2 ADSCs combined with Mel treatment group.
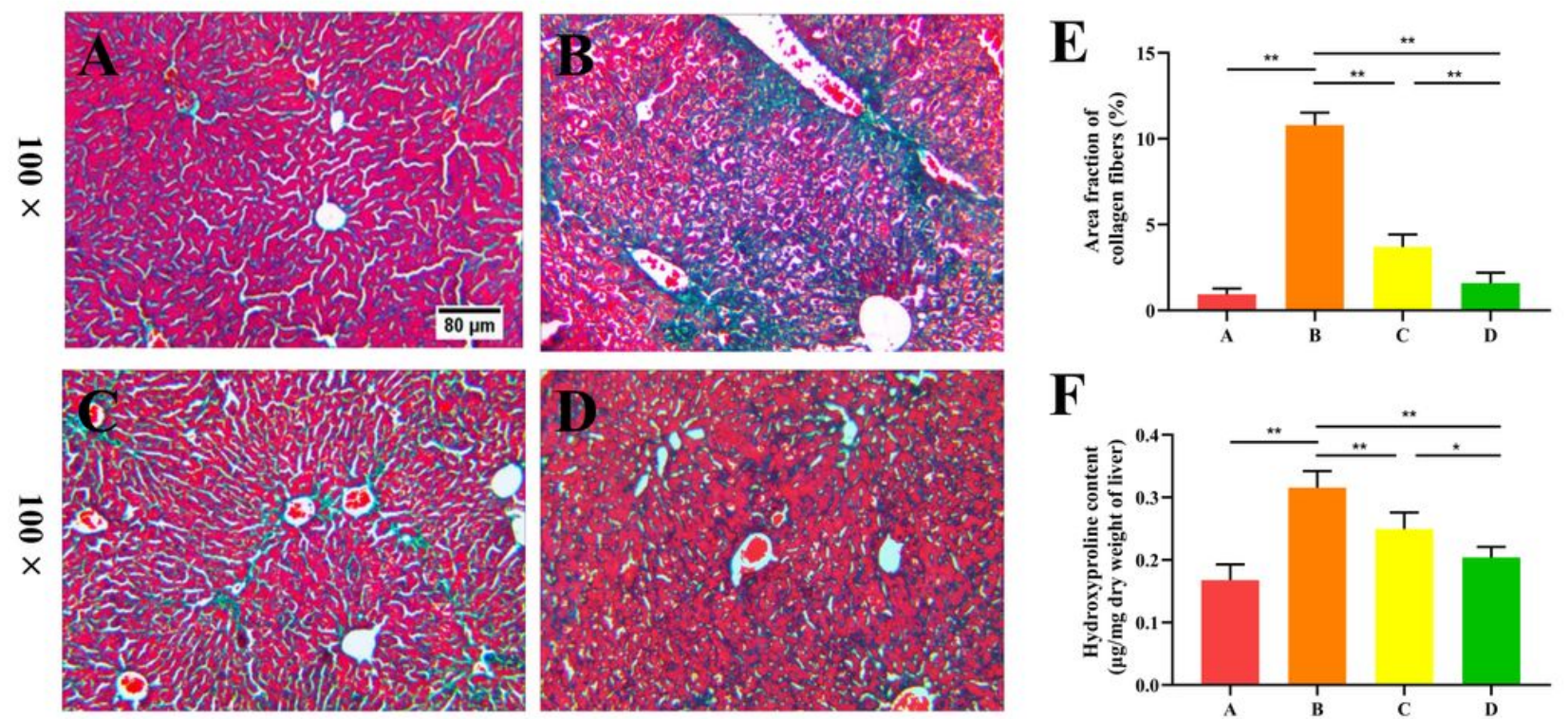
Figure 3

The effect of Mel-incubated ADSCs on CCl4-induced liver fibrosis. A Control group, B Model group, C ADSCs treatment group, D ADSCs combined with Mel treatment group. E Area of fibrosis (here the collagen fibers are dyed green). F HYP content. Note: *indicates significant, $P<0.05$; $*$ *indicates extremely significant, $\mathrm{P}<0.01$.
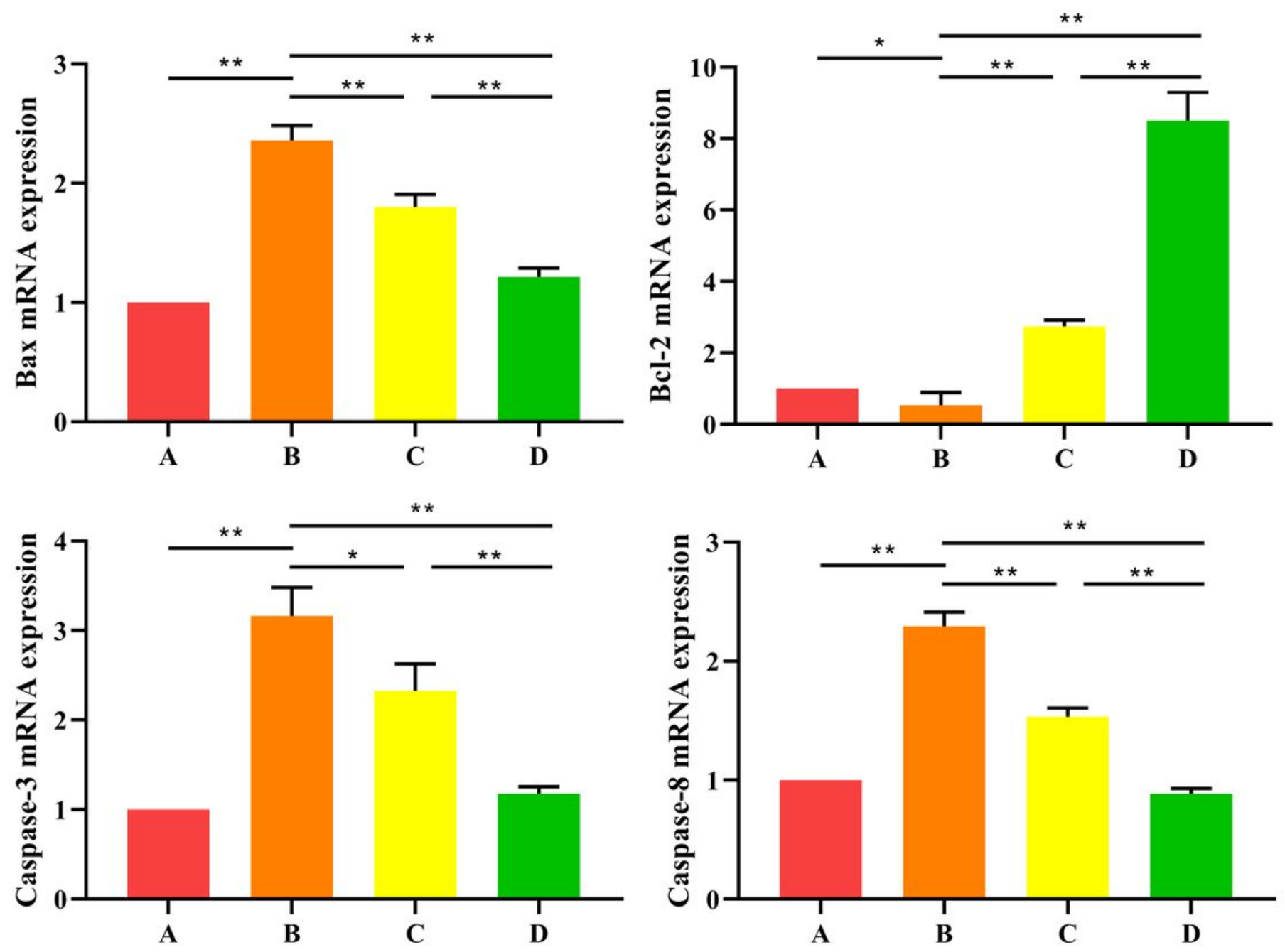

Figure 4

Effect of Mel incubation ADSCs on CCl4-induced apoptosis of hepatocytes. A Control group, B Model group, C ADSCs treatment group, D ADSCs combined with Mel treatment group. Note: *indicates significant, $\mathrm{P}<0.05$; $*$ indicates extremely significant, $\mathrm{P}<0.01$. 

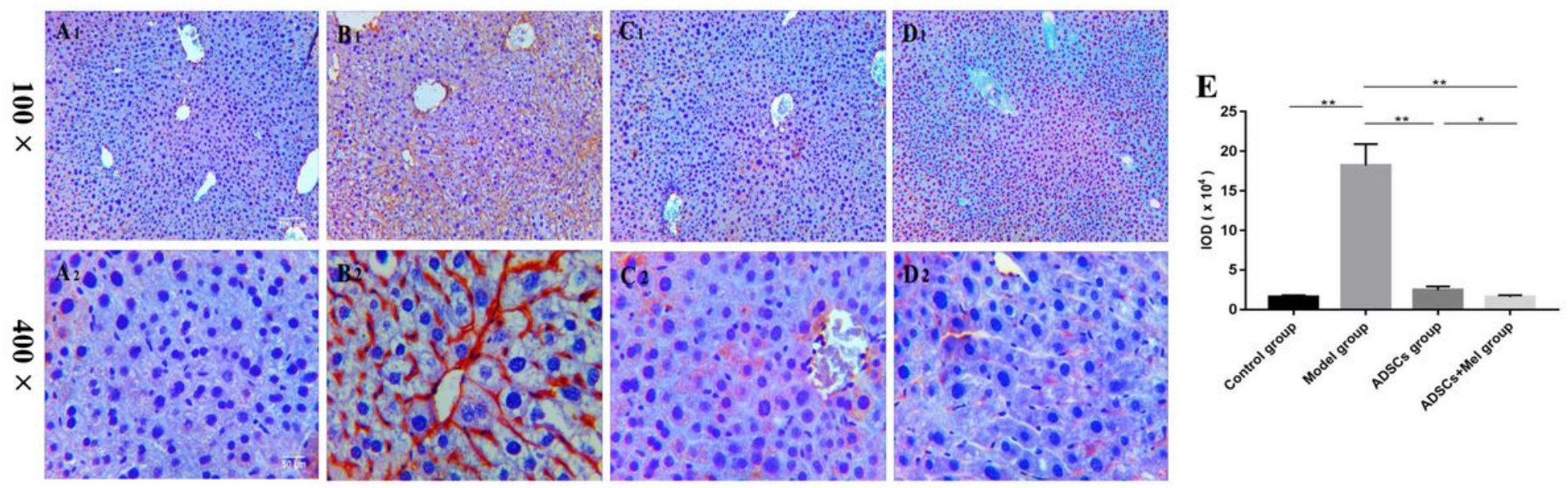

\section{Figure 5}

Effects of Mel-incubated ADSCs on the expression of MMP-2 in CCl4-induced liver. A1, A2 Control group. B1, B2 Model group. C1, C2 ADSCs treatment group. D1, D2 ADSCs combined with Mel treatment group. E IOD value of MMP-2. Note: *indicates significant, $\mathrm{P}<0.05$; $*$ indicates extremely significant, $\mathrm{P}<0.01$. 

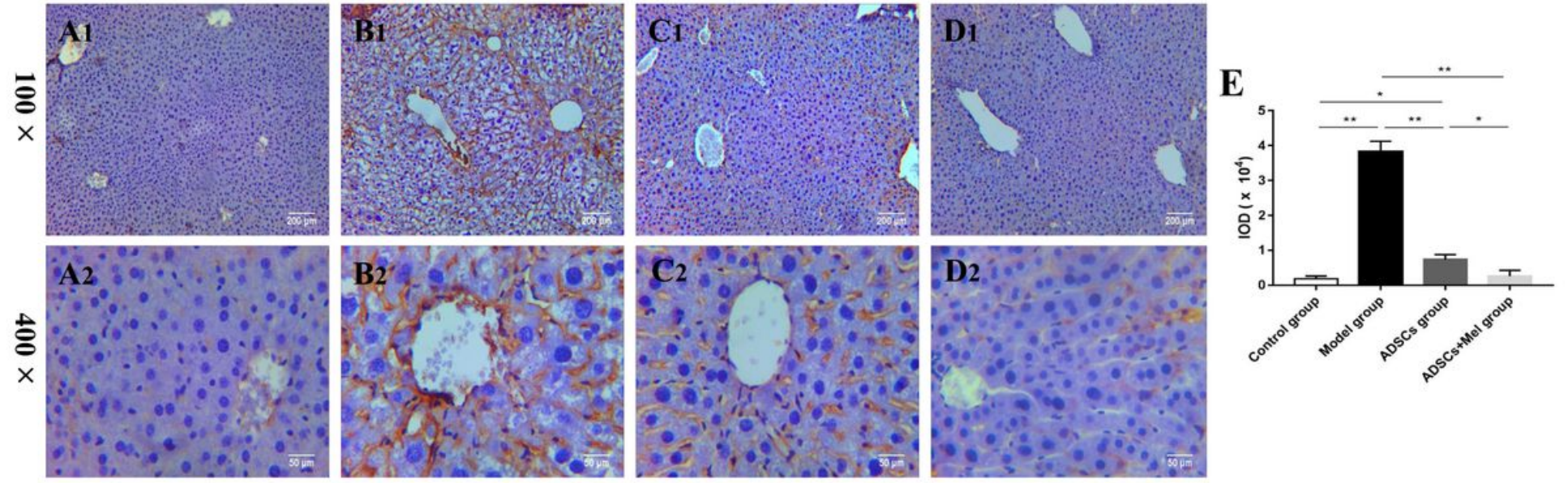

\section{Figure 6}

Effects of Mel-incubated ADSCs on the expression of MMP-9 in CCl4-induced liver. A1, A2 Control group. B1, B2 Model group. C1, C2 ADSCs treatment group. D1, D2 ADSCs combined with Mel treatment group. E IOD value of MMP-9. Note: *indicates significant, $\mathrm{P}<0.05$; $*$ indicates extremely significant, $\mathrm{P}<0.01$. 

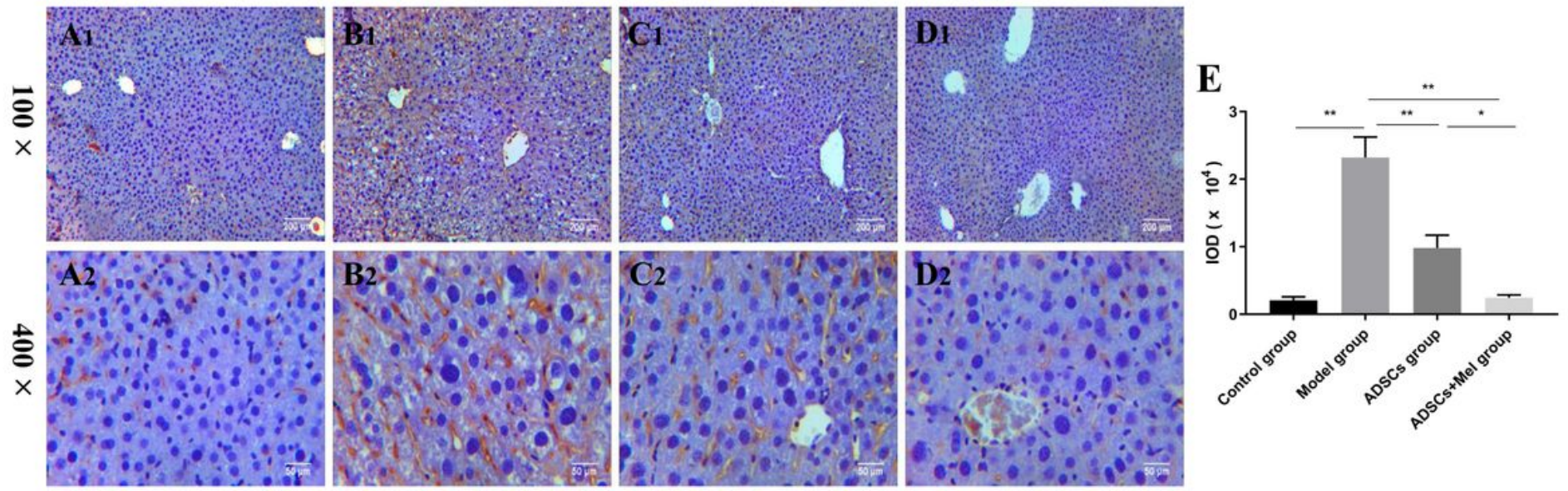

\section{Figure 7}

Effects of Mel-incubated ADSCs on the expression of TGF- $\beta$ in CCl4-induced liver. A1, A2 Control group. B1, B2 Model group. C1, C2 ADSCs treatment group. D1, D2 ADSCs combined with Mel treatment group. E IOD value of TGF- $\beta$. Note: *indicates significant, $P<0.05$; **indicates extremely significant, $P<0.01$. 